\title{
Perspectives in Water Quality Assessment
}

\author{
N D S S Kiran Relangi, Aparna Chaparala, Radhika Sajja
}

\begin{abstract}
One can assess the quality of water by water quality index method and it is a mathematical method to evaluate the water quality based on physical or chemical parameters, using WQI one can evaluate the water quality of both ground water and surface water, while determining the WQI one can use the standards or guidelines provided by some standard organizations like WHO (world health organization), National Standard Body of India (BIS), ICMR (Indian Council for Medical Research) etc. To assign grade to the water samples under study, apart from the WQI there are some other popular techniques used to evaluate water quality they are statistical methods, multivariate statistics, neural networks, fuzzy logic and machine learning algorithms. The aim of this study is to give insight into various methods used or developed to evaluate water quality of both ground and surface water by earlier research works.
\end{abstract}

Index Terms: Cluster Analysis, Principal Component Analysis, Factor Analysis, Multivariate Statistics, Geographic Information Systems, Water Quality Index, Artificial Neural Networks, Absolute Principal Component Sources, Multi Linear Regression, Long Short Term Neural Network, Absolute Principal Component Sources-Multi Linear Regression, Multilayer Perceptron Neural Network, Radial Basis Function

\section{INTRODUCTION}

Good quality of any resource will lead to good things. Compromise in water quality will lead to certain problems ranging from minor health problems like skin diseases to major health complications like bone disorders, chronic kidney diseases etc. So in order to overcome the issues raised by pollutant water the first need is to be identifying the pollutants and then there are various methods to address this issue, some of them are to identify the pollutant sources of water in terms of human activities, temporal variations, ecological or climatic conditions. Once the pollution sources of water are identified then it is easy to deal with those issues to get fresh or quality water.

Mainly the water is polluted by anthropogenic activities like more population, urbanization, waste water runoff, municipal water runoff, industries like automobile, chemical, painting and agricultural waste which are directly dumped into nearby surface water or surrounding lands. Hence there should be a need for water management, which can done by water sampling networks for water quality

Revised Manuscript Received on July 05, 2019.

N D S S Kiran Relangi, Research Scholar (Part-Time), Department of CSE, College of Sciences, Acharya Nagarjuna University, Guntur-522510, India.

Aparna Chaparala, Associate Professor, Department of CSE, RVR \& JC College of Engineering, Guntur-522019, India.

Radhika Sajja, Professor, Dept of Mechanical Engineering, RVR \& JC College of Engieering. Guntur-522019. India. management by means of mathematical, statistical methods and other advanced techniques like data analysis and

clustering to identify the quality of water and to examine apportionment pollution sources. The objective of this study is to review various research methods adopted by previous researchers to address the issue of water quality, also to analyze and understand measures suggested to overcoming this issue by earlier research studies.

The aim of this comprehensive study is to present perspectives in surface and ground water excellence determination. Some authors worked out on how to assess the water quality using a well known direct method called Water Quality Index by considering physico-chemical or biological parameters, some researchers used Cation and Anion parameters to determine water quality index. In addition to calculate water quality index some researchers took the help geographic information systems like GIS maps to accurately identify the polluted stations, some researchers not only assessed the water quality but also identified the polluting sources, the percentage of pollution sources assessed that leads to contaminated water, environmental, climatic conditions, anthropogenic activities there by degrading the quality of water. Some researchers emphasized on identifying whether the water quality is near to mineral water or not. Most of the studies that were conducted by the researchers rely on statistical and data mining techniques.

\section{WATER QUALITY INDEX}

The objective of this study is to bring out the quality of given water samples to identify the suitability of urban water body in Shimoga town by capturing data samples considering 13 physico chemical variables like EC, TDS, T-Alk, T-Hard, TSS, pH Calcium, Magnesium, Chlorides, Nitrate and $\mathrm{SO}_{4}$, Do and BOD, in three seasons rainy, winter and summer. To calculate WQI of the water body, the researchers follow the standards given by standard organizations like WHO (world health organization). The results obtained after applying weighted arithmetic index method of WQI reveals that the quality of water is not suitable for human consumption it also noticed that water pollution is high in summer season[14].

In this study authors Pradeep Kumar Sharma, Ritu Vijay et al. developed a method to assess the ground water quality as well as to identify the relation between ground water and rainfall, of large region Rajasthan state located in India by water quality indexing and generating WQI maps using Geographic Information System (GIS) technique [15]. The authors intention behind assessing ground water quality

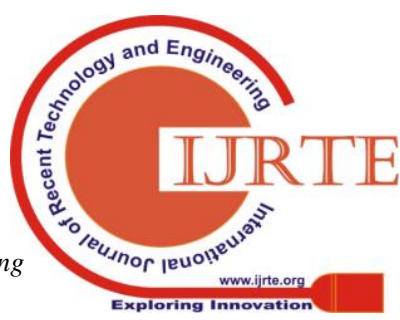


is that there is lot of scarcity for surface water in this study area and most of the rural, areas are not connected with the surface water system hence they are completely depended on ground water resources, the ground water in some regions of Rajasthan State is saline and other issues affecting the ground water quality like Litho logy, geomorphology, climate and anthropogenic activities, due to these factors it is very essential to evaluate the quality of ground water to verify it is suitable for drinking purpose or not. This study is done on the data samples with 10 water quality parameters TDS, $\mathrm{Na}+\mathrm{K}+$, $\mathrm{Ca} 2+, \mathrm{Mg} 2+, \mathrm{Cl}-, \mathrm{SO} 4-, \mathrm{NO} 3-, \mathrm{F}-$ and $\mathrm{TH}$ are captured from 700 wells from the period of 2007 to 2013 . In this preliminary study, it is identified that NO3, TDS and Na+ have significant impact on ground water quality, after calculating the WQI of data samples. The authors generated ground water quality maps with rainfall maps using GIS to determine the relation between ground water quality and rainfall. This step leads to witness that when rains were more than average as a result ground water quality was improved. Finally this work leads to evaluate quality of ground water and disseminate it to the people residing in the study area.

A successful attempt has been made to assess the quality of ground water and determine the impact of water quality parameters that degrade water quality, of Aligarh City located in India, by Water Quality Index method. To identify the sampling locations or sites in which type of water quality they belongs to like excellent, good or bad water quality. In order to perform this work they captured 80 water samples from 40 sampling locations in post monsoon and pre monsoon seasons. All these captured samples are subject to 14 physico chemical parameters, they are $\mathrm{pH}$, TDS, Turbidity, Hardness, Chloride, Sulphate, Total Alkalinity, Fluoride, Iron, Calcium, Magnesium, Nitrate, Zinc and Copper, all these physico chemical parameters samples data are analyzed according to the standards given by BIS for drinking water specification [17]. After calculating the WQI values of each data sample, the researchers assigned water quality grade based on a number of water pollution studies for suitability of water for human consumption. This work indicates that 4 locations at the time of pre monsoon and 5 locations of after monsoon season of the study are excellent in water quality, the remaining sampling sites falls into the category between good to moderately contaminated, the researchers also identified that Alkalinity, magnesium, hardness, iron, $\mathrm{pH}$, calcium and TDS are the parameters which leads to water quality deterioration as per BIS standards.

\section{III.SURFACE WATER EXCELLENCE}

Surface water is polluted due to urbanization, anthropogenic activities, waste water runoff from residential areas, industrial areas directly into nearby surface water sources like rivers and other surface water sources; hence it is essential to estimate the surface water quality. This section gives a comprehensive study of earlier researches to assess surface water quality.

In year 2005, the researchers adopted MST to assess quality of surface water and recognize the pollution sources [1]. The authors collected data samples from the study area of the Gomti river (India), the data samples captured from 1999-2001, at eight different sites for 34 parameters. The authors first applied cluster analysis to form three clusters of the sampling locations. The sampling sites that fall into first cluster are low polluted, the sampling sites that belong to second cluster are highly polluted and the sampling sites that fall into third cluster are moderately polluted, authors applied Spearman correlation coefficient and Discriminant Analysis to point out temporal change in water excellence which helps to identifying the parameters they are $\mathrm{T}$, alkalinity, $\mathrm{Cl}, \mathrm{Na}$ and $\mathrm{K}$ which cause temporal changes in quality of river water, the usage of DA also suggests that anthropogenic activities leads to pollution of river water. The authors applied PCA and FA on data samples by considering 26 parameters they found the sources of apportionment by multi liner regression on absolute principal component sources (APCS-MLR) in forming clustered regions, in these three clustering regions the sources influencing river quality is anthropogenic activities.

There was a study done in year 2007, to judge the quality of logged water at an irrigation project, the authors applied multivariate statistical techniques and considered most of the hydro chemical parameters in the assessment of water quality inclusion of parameters those are not used in earlier conventional techniques [2]. The area from the data samples are collected is susceptible to contamination due to agricultural activities. The researchers collected 34 data samples, fifty percent of the samples collected in summer season and rest of them are collected in winter season. The data samples are analyzed for 23 water quality parameters. The aim of this work is to determine the environmental influences of agricultural activities in the study area and to find out quality of water. Trace elements are nontrivial in this work and which were not considered in conventional techniques; by using this method the authors categorize the water into three types and is polluted by two factors; they are ions pole and trace elements. This study reveals that usage of fertilizers and pesticides is high in winter season.

The researchers applied some methods in MST to assess quality of surface water of Ebro River (Spain), hey collected data from 13 sampling stations of 34 physical-chemical parameters over a period of 24 years [5]. The researchers applied parametric, non parametric methods including PCA and cluster analysis of the historical data set collected from 24 years. The results of this study reveals that the sources of pollution are anthropogenic, climatic, geogenic and turbidity, the authors are also applied water quality index method to identify the trend in the study area and found that an upward trend at one sampling site (Site8), downward trend at 9 sampling stations (Site1, Site2, Site5, Site6, Site7, Siste9, Site10, Site11 and Site13) and no trend found in three sites (Site3, Site4 and Site12).

The researchers in [7] measure surface water quality of Jining River, using probabilistic neural network and fuzzy inference system. They consider BOD, Chemical oxygen demand, $\mathrm{NH}_{3}-\mathrm{N}$, Dissolved oxygen as parameters to determine the water quality along with the standards given by the surface water quality guidelines issued by the China Government. Researchers collected data samples of the Jining River from the years 1999-2002, this work reveals that the water quality of stations South Marine and

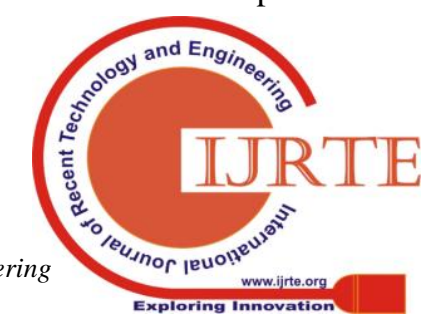


South Wahuan in all seasons is poor.

Application of hybrid neural network model called FNN model to judge the quality of water Suzhou was studied [8]. FNN is a hybrid model composed using RBN (Radical Basis Network) and (CNN) Compete Neural Network. They have collected data samples from Suzhou surface area in 1999-2002 time periods. Parameters used in this study to evaluate the quality of surface water were CODcr, Dissolved oxygen, $\mathrm{NH}_{3} \mathrm{~N}, \mathrm{BOD}_{5}$. The data samples are divided into five groups based on surface water quality guidelines issued by the China Government. By this work, authors successfully assessed quality of water at different sampling sites.

Two different types of artificial neural networks namely back propagation and Radial bias function neural networks, used in assessing the quality of water of Fuyang River in Hand City, these two models performance is considered in [9]. The authors have collected data samples from 14 distinct sampling stations; the samples posses the water quality parameters Dissolved oxygen, $\mathrm{COD}_{\mathrm{Mn}}, \mathrm{COD}_{\mathrm{cr}}$, $\mathrm{BOD}_{5}$ and $\mathrm{NH}_{3} \mathrm{~N}$, therefore each network have five input neurons and one output neuron. They assigned the grade of each data sample by following the standard GB3838-2002. This research work reflects that quality of considered river water is 3 by both network models and also observed that among the two neural network models, Radial Bias Function neural network is better model in terms of training error in the learning process.

In this work the researchers proposed a model to assess the quality of surface water using Artificial Neural Networks (ANN). The backbone of the proposed model is Back Propagation Neural Network. The researchers gathered data samples from three sampling locations (Lancum Village, Shitan Patch, Hejin) with 7 water quality parameters, they are DO, Volatile Phenol, COD, Cyanide, $\mathrm{Hg}$, As and $\mathrm{C}_{\mathrm{r}}^{6+}$. In the proposed model the back propagation network was improved by means of select required number of configurations like number of hidden layers, nodes in the layers etc, in determining the surface water quality. Finally this work indicates that proposed back propagation model was ahead among traditional and back propagation water quality evaluation models [10].

In this research work the authors construct a model called ANN with time series Nonlinear Autoregressive (NAR) based on machine learning algorithms is to forecast the excellence of water. The data samples captured along with time is collected from the United States Geological Survey online resource called National Water Information System (NWIS). Water samples subjected to 4 parameters they are DO, Chlorophyll, $\mathrm{T}$ and Specific Conductance, these will effect and influence water quality [11]. The constructed model is applied once for each of the parameters. Hence the model is executed four times to determine the quality of each parameter. While determining the efficiency of the parameters they considered metrics are Mean Squared Error and Root Mean Squared Error [11].

The researchers, Proposed a method based on LST neural network to predict water quality of Taihu Lake, they tested the proposed model with two other neural network models namely back propagation and online sequential extreme learning machine, and found that proposed method performance is high. The data set comprises of 657 samples used in this study were collected from Taihu Lake from 2000 to 2006. The proposed network is used to predict water quality parameter values of TP and DO. This work reflects that the proposed model predicts the water quality parameters DO and TP with high accuracy than the other two models, and also the proposed method is more suitable to handle time series water quality data, rather than the other two models considered in this work [12].

Application of ANN in water quality prediction of Johor River Basin located at Johor state, Malaysia has been reviewed [13]. There are huge numbers of parameters that are used in water quality determination or prediction, in this work the authors acquired data samples from two sampling locations Main Stream and tributary, with three water quality parameters, they are, Total Dissolved Solids (TD), Electrical Conductivity (EC) and Turbidity. Researchers applied three different kinds of neural networks to predict water quality. The networks are LRM, MLPNN and RBF, the researchers experimented with different architectures of the considered three networks by selecting different configurations of the networks like total neurons in each layer, type of activation function, total hidden layers etc,. After training and testing the networks to water quality prediction, it clearly indicates that RBF network is the best model among the other two networks because it has high accuracy and lowest error rate.

\section{GROUND WATER EXCELLENCE}

Most of the areas under study are not connected with municipal water system due to various reasons therefore these area purely depend on ground water for their purposes, therefore assess the ground water quality is an non trivial issue and to know the quality of water because all the living beings use the ground water for all their purposes. As stated earlier in this work, polluted water leads to many health problems ranging from skin diseases to bone disorders and consumption of polluted water also leads to various other problems like damage of washing machines, purifiers, clothes etc. The following section reviews different methods used or proposed by the earlier research to assess quality of the ground water.

In this study, the researchers used multivariate statistical techniques for determining ground water quality along with the pollution sources and categorization of sources those cause pollution which degrades quality of water. The researchers collected 68 data samples with 14 physicochemical parameters from the study area, in pre monsoon and post monsoon seasons. The sampling was conducted at various sites like polluted areas, commercial areas, industrial and residential colonies from bore wells to get a good sample representation. The parameters are Electrical conductivity, Total Dissolved Solids, Potential Hydrogen, $\mathrm{Mg} 2+, \mathrm{Ca} 2+, \mathrm{Na}+, \mathrm{K}+, \mathrm{Fe}, \mathrm{Cl}-$, Sulphate, $\mathrm{HCO} 3, \mathrm{TH}, \mathrm{NO} 3-$ and F-. The preliminary data analysis reveals that concentration of each parameter is low in pre monsoon season compared with post monsoon season. Parameters used in assessment of ground water quality are $\mathrm{TH}, \mathrm{TDS}, \mathrm{Fe}, \mathrm{Ca}^{2+}$ and $\mathrm{Mg}^{2}$ exceeds its required limit, it

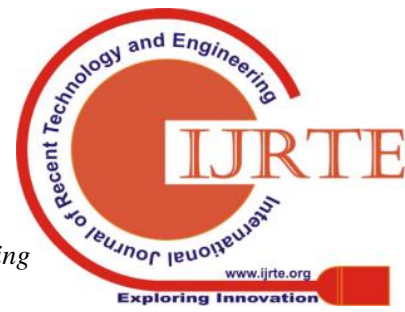


shows that the quality of ground water is lower than the desirable. The researchers applied PCA to the collected data samples after performing preliminary data analysis and found the sources those cause pollution are bedrocks, septic tank sewage, sewage from industrial area and some sources from geogenic. Finally the researchers applied APCS-MLS MLR technique to source apportionment and found that the parameters TDS, EC, $\mathrm{TH}, \mathrm{Ca}^{2+}$ and $\mathrm{Mg}^{2+}$. Along with these parameters there are unidentified sources which also cause pollution in the study area [6].

\section{GROUND \& SURFACE WATER EXCELLENCE}

Application of MST to assess the influence of metals and other elements of ground water surface water and in Patancheru industrial area near Hyderabad (India) is reviewed [3]. Number of textile, pharmaceutical and chemical industries is established nearby to the study area and susceptible sources of pollution from these industries are dumped into sources that are origin of ground water. It is also identified as one of the most polluted area by some standard organization, and considered as ecological disaster. In order to assess the pollution sources they consider some trace elements those are included in water quality assessment parameters that have been collected from fifty three sampling stations. The authors first applied PCA to the dataset and identified factors which deteriorate the surface water, Factor 1 reveals that arsenic contamination in surface water comes mainly from paint, pharmaceutical, fertilizers and pesticides industries, Factor2 reveals that the surface water is deteriorated by anthropogenic and geogenic sources, Factor3 indicates that agricultural activities on the trace elements in surface water, Factor4 indicates that geogenic process lead to surface water deterioration. Factor 1 of the groundwater indicates the anthropogenic influence of the trace elements in the ground water, Factor 2 of the groundwater indicates that the geochemical nature is the main pollution source.

\section{CONCLUSION}

An attempt has been made to review various methods which have already existed, proposed methods and models used in water quality assessment, based on this review it is observed that quality of water depends on pre monsoon and monsoon seasons, sampling locations and anthropogenic activities. The most significant factor which degrades water quality is anthropogenic activities.

\section{REFERENCES}

1. K. Yogendra and E.T. Puttaiah, "Determination of Water Quality Index and Suitability of an Urban Waterbody in Shimoga Town, Karnataka," World Lake Conference, pp. 342-346, 2008.

2. Pradeep Kumar Sharma, Ritu Vijay and M.P. Punia, "Ground Water Quality Assessment using Waster Quality Index and GIS in Rajasthan, India," International Journal of Advances in Remote Sensing, GIS and Geography, Vol.4, No.2, pp. 12-26. 2016.

3. Khwaja M. Anwar and Vanita Aggarwal, "Analysis of Groundwater Quality of Aligarh City, (India): Using Water Quality Index", An International Research Journal of Environmental Science, ISSN: 0973-4929, 2014-09-21, http://dx.doi.org/10.12944/CWE.9.3.36.

4. Kunwar P. Singh, Amrita Malik and Sarita Sinha, "Water quality assessment and apportionment of pollution sources of Gomti river(India) using multivariate statistical techniques-a case study," Analytica Chimica Acta, pp. 355-374, March 2005.

https://doi.org/10.1016/j.aca.2005.02.006.
5. Mahbub Hussain, Syed Munaf Ahmed, Walid Abderrahman, "Cluster analysis and quality assessment of logged water at an irrigation project, estren Saudi Arabia," Journal of Environment Management, pp. 297-307, June 2007. (References). https://doi.org/10.1016/j.jenvman.2006.12.007.

6. R. Bouza-Deano, M. Ternero-Rodriguez and A.J. Fernandez-Espinosa, "Trend Study Assessment of surface water quality in the Ebro River (Spain)," Journal of Hydrology, pp. 227-239, July 2008 (references). https://doi.org/10.1016/j.jhydrol.2008.07.048.

7. J Changiun Zhu and Zhenchun Hao, "Application of Probabilistic Neural Network Model in Evaluation of Water Quality," ICESIAT2009, pp. 244-247, 2009. DOI: 10.1109/ESIAT.2009.36.

8. Changjun Zhu and Zhenchun Hao, "Fuzzy Neural Network Model and its Application in Water Quality Evaluation," ICESIAT2009, pp. 251-254, 2009.DOI: 10.1109/ESIAT.2009.45.

9. Simin Li, Nannan Zhao, Zhennan Shi and Fengbing Tang, "Application of Artificial Neural Network on Water Quality Evaluation of Fuyang River in Hand City," 2010 International Conference on Mechanic Automation and Control Engineering, pp. 1829-1832, 26th-28th June 2010

10. XUE Xicheng and CHEN Yan, "Water Quality Evaluation of Surface Water Based on Back Propagation Neural Network", 2011 International Symposium on Water Resource and Environmental Protection (ISWREP), $20^{\text {th }}-22^{\text {nd }}$ May, 2011.

11. Yafra Khan and Chai Soo See, "Predicting and Analyzing Water Quality using Machine Learning: A Comprehensive Model," 2016 IEEE Long Island Systems, Applications and Technology Conference (LISAT), $29^{\text {th }}$ April 2016.

12. Yuanyuan Wang, Jian Zhou, Kejia Chen, Yunyun Wang and Linfeng Liu, "Water Quality Prediction Method Based on LSTM Neural Network," 2017 12th International Conference on Intelligent Systems and Knowledge Engineering (ISKE), 24 ${ }^{\text {th }}-26^{\text {th }}$ November 2017 (Journal Online Sources style) K. Author. (year, month). Title. Journal [Type of medium]. Volume(issue), paging if given. Available: http://www.(URL)

13. A. Najah, A. EI-Shafie, O.A. Karim and Amr h. EI-Shafie, "Application of artificial neural networks for water quality prediction", Neural Computing and Applications, Volume 22, Supplement 1, pp 187-201, May 2013.

14. Mohammad Shahid Gulgundi and Amba Shetty, "Identification and apportionment of pollution sources to groundwater quality," Journal of Environmental Processes, vol.3, Issue.2, pp. 451-461, $1^{\text {st }}$ June 2016.

15. Aradhi K. Krishna, M. Satyanarayana and Pradip K. Govil, “Assessment of heavy metal pollution in water using multivariate statistical techniques in an industrial area: A case study from Patancheru, Medak District, Andhra Pradesh, India," Journal of Hazardous Material, pp. 366-373, January 2009.

\section{AUTHORS PROFILE}

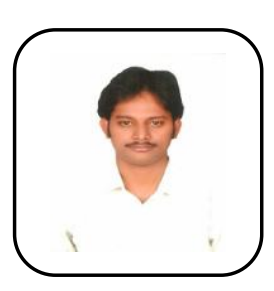

N D S S Kiran Relangi working as Assistant Professor in Dept. of MCA, Swarnandhra College of Engineering \& Technology, he is part time research scholar in Dept of CSE, Acharya Nagarjuna University, Guntur, and A.P, INDIA. He revived MCA degree in 2007 from Andhra University, received M.Tech (CSE) master degree from JNTUK-Kakinada. He is working on Water Quality Assessment though Machine Learning.

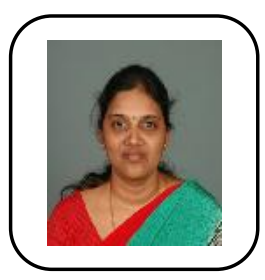

Dr. Aparna Chaparala completed her Ph. D in Data mining at JNTU, Hyderabad and M. Tech (CSE) from Andhra University College of Engineering, Vishakhapatnam. At present she is working as Associate Professor in Dept of CSE, RVR \& JC College of Engineering, Guntur. Also she is supervising research scholars in computer science at Acharya Nagarjuna University. She has many research publications in the field of computer science, her areas of interest are Data Mining, Artificial Intelligence, and Machine Learning. 


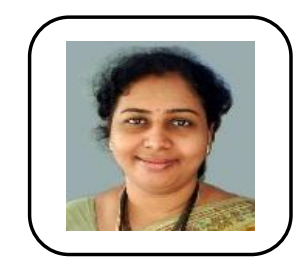

Dr. Radhika Sajja, is currently working in the Department of Mechanical Engineering at RVR \& JC college of Engineering. She published many research papers in the field of manufacturing and optimization. She is also editorial board member for few journals. Her areas of interest include Robotics, Sustainable Energy systems and Computer integrated manufacturing. 